Check for updates

Cite this: New J. Chem., 2017, 41, 11546

Received 29th June 2017, Accepted 5th September 2017

DOI: $10.1039 / c 7 n j 02328 f$

rsc.li/njc

\title{
$\beta-0-4$ type dilignol compounds and their iron complexes for modeling of iron binding to humic acids: synthesis, characterization, electrochemical studies and algal growth experiments $\dagger$
}

\author{
Ewelina Orlowska, ${ }^{a}$ Éva A. Enyedy, (DD ${ }^{\mathrm{b}}$ Marc Pignitter, ${ }^{c}$ Franz Jirsa, (D) ad \\ Regina Krachler, (D) ${ }^{a}$ Wolfgang Kandioller (D) ${ }^{a}$ and Bernhard K. Keppler ${ }^{a}$
}

\begin{abstract}
A series of $\beta-O-4$ type dilignols and their iron(III) complexes, designed as model compounds for humic acids, were prepared and characterized by ${ }^{1} \mathrm{H}-\mathrm{NMR}$ and ${ }^{13} \mathrm{C}-\mathrm{NMR}$ spectroscopy, elemental analysis, EPR, IR and UV-Vis spectroscopies and electrospray ionization mass spectrometry (ESI-MS). Properties regarding iron binding, stability, lipophilicity and bioavailability for microorganisms have been evaluated with cyclic voltammetry, stability studies in water and seawater by means of UV-Vis spectrophotometry and the algae growth assays with seawater algal species Chlorella salina and Prymnesium parvum. Both established ligands and their iron complexes undergo deprotonation processes in seawater whereas no changes in UV-Vis spectra were observed in distilled water. The iron(III) complex formation constants, $\mathrm{p} K_{\mathrm{a}}$ values and lipophilicity of the dilignols were in the same range as for the analogous catechol coordination compound. Synthesized dilignols were prone to redox reactions under biological conditions similar to natural aquatic humic acids. Moreover, an increased iron bioavailability was observed for the presented complexes compared to corresponding catechol complexes and comparable to the bioavailability of iron bound to humic acid complexes recovered from Craggie Burn river. Those results confirm that $\beta-O-4$ type dilignol compounds are excellent model ligands for aquatic humic acids.
\end{abstract}

\section{Introduction}

Iron chemistry in seawater and its bioavailability for microorganisms have been intensively investigated for a long time. ${ }^{1-4}$ Several experiments have shown that iron is limiting the productivity of marine ecosystems in huge areas of the ocean $^{5-9}$ but only little is known about the chemical speciation of iron in seawater and its accessibility for phytoplankton. Iron is not only an important factor for growth of algae and other microorganisms but also selectively supporting the development and expansion of several species (with lower iron demand), which

\footnotetext{
${ }^{a}$ Institute of Inorganic Chemistry, Faculty of Chemistry, University of Vienna, Waehringer Str. 42, A-1090 Vienna, Austria.

E-mail: wolfgang.kandioller@univie.ac.at; Fax: +43-1-4277-9526; Tel: +43-1-4277-52609

${ }^{b}$ Department of Inorganic and Analytical Chemistry, University of Szeged, Dóm tér 7, H-6720 Szeged, Hungary

'Department of Physiological Chemistry, Faculty of Chemistry, University of Vienna, Althanstr. 14/UZA II, A-1090 Vienna, Austria

${ }^{d}$ Department of Zoology, University of Johannesburg, Auckland Park, 2006, South Africa

$\dagger$ Electronic supplementary information (ESI) available: Detailed information about materials, methods and syntheses. See DOI: $10.1039 / \mathrm{c} 7$ nj02328f
}

impacts the food chain within the whole ecosystem. ${ }^{4,10}$ Analytical methods provide information about the concentration of dissolved and undissolved iron or iron solubility dependent on the presence of organic ligands. However, exact structures of bioavailable iron complexes and uptake mechanisms remain still unclear. There are several factors influencing iron bioavailability for microorganisms. Besides different uptake mechanisms, kinetics and iron requirements for each species, one pressing issue is the chemical form of bioavailable iron. It is known, that inorganic iron displays an extremely low solubility in seawater, which is the result of the low solubility of iron oxide (the general term 'iron oxide' describes various forms of iron oxide, oxyhydroxide and amorphous iron hydroxide). ${ }^{11,12}$ Thus, almost all of dissolved iron in the ocean is bound to organic scaffolds. ${ }^{13-16}$ Those ligands have a large range of different structures and origins. One group of them are siderophores, which are produced by bacteria particularly in order to complex iron(III). ${ }^{17-19}$ Stability constants for iron complexes of these natural chelators are extremely high and special mechanisms have been developed by certain organisms to release the iron from complexes formed. ${ }^{20}$ Another big group of important iron chelators are substances which originate from decomposition of organic material, known as humic substances. Their main sources are 
rivers, especially derived from peat bog regions which are rich in aquatic humic substances (AHS). It has been shown, that AHS are greatly improving the bioavailability of iron in coastal waters. ${ }^{21-25}$ Also algal studies on microalgae Chlorella salina and Diacronema lutheri in batch cultures support the assumption of the positive impact of AHS on iron supply. ${ }^{26}$ Algal cultures treated with isolated AHS showed increased growth response compared to samples treated with iron(III) chloride and EDTA (ethylenediaminetetraacetate), a complexation agent used for commercial algal cultivation ${ }^{27}$ ). Knowing the importance of those chelators on phytoplankton growth and vitality, which affect huge amount of other processes like for example the global $\mathrm{CO}_{2}$ cycle ${ }^{28-30}$ it is of great interest to clarify the chemistry behind iron complexation, release and uptake as well as the structure of the complexes and ligands. Unfortunately, research on humic substances, especially AHS is very challenging due to their low concentration in seawater ${ }^{31}$ and the structural complexity depending on origin, incorporated building blocks and formation processes. ${ }^{32-35}$ In order to understand the chemistry of AHS regarding iron binding properties and the postulated release by photoreduction $^{36}$ the utilization of model systems represents a highly promising approach. In our previous studies, we synthesized simple iron complexes with different coordination motifs and ligand scaffolds and investigated them for their suitability as model compounds for humic acids iron complexes. ${ }^{37}$ The model compounds were characterized and investigated by various analytical techniques (cyclic voltammetry, EPR, EXAFS, ${ }^{36}$ UV-Vis spectroscopy etc.) in addition to algal batch culture studies on chlorophyte and haptophyte unicellular algae species. The results of the latter assays led to the conclusion, that catechol-based ligand systems are excellent scaffolds for modeling of iron-AHS complexes. Therefore catechol-derived ligands and complexes with structural characteristics and molecular weight in range of natural AHS were established. The main components of humic substances are lignin decomposition products, originating from support tissues in plants and guaiacylglycerol- $\beta$-guaiacyl ether represents a suitable model for lignin. ${ }^{38,39}$ Binding studies of iron with guaiacylglycerol- $\beta$-guaiacyl ether precursors (coniferyl alcohol, sinapic acid, ferulic and coumaric acid) and dehydrogenation polymers of coniferyl alcohol have been already carried by Guillon et al. regarding their sorption properties in comparison to lignin. ${ }^{40,41}$ Although guaiacylglycerol- $\beta$-guaiacyl ether seems to be a good model for AHS, formation of stable iron complexes is unlikely. For this reason, we decided to modify the $\beta-O-4$ backbone of guaiacylglycerol- $\beta$-guaiacyl ether by introduction of a free catecholic moiety. In this work we report the synthesis of diastereomerically pure lignols designed as model compounds for AHS, bearing free catecholic groups and their respective iron complexes. The synthesized substances were characterized by elemental analysis, spectroscopic methods (IR, EPR, UV-Vis), NMR spectroscopy (in the case of the ligands), mass spectrometry (ESI-MS) and cyclic voltammetry. The proton dissociation constants $\left(\mathrm{p} K_{\mathrm{a}}\right)$, complex formation constants and lipophilicity (as distribution coefficients) were determined. The bioavailability of the respective iron coordination compounds was elucidated in two unicellular algal species, namely chlorophyta Chlorella salina and haptophyte Prymnesium parvum in batch cultures.

\section{Results and discussion}

\section{Synthesis - general overview}

Diastereomerically pure guaiacylglycerol- $\beta$-guaiacyl ether 6a was synthesized according to previously published procedure. ${ }^{42}$ Two novel $\beta-O-4$ type lignol compounds $\mathbf{6 b}, \mathbf{c}$ were synthesized in a similar approach (Scheme 1, see ESI $\dagger$ ). Compound 3 was prepared according to the procedure described by Nakatsubo et al. ${ }^{43}$ using tert-butyl chloroacetate. Aldehydes bearing free phenolic groups were protected with benzyl groups to avoid undesired side reactions (2a-c). Condensation of $\mathbf{3}$ and $\mathbf{2 a}-\mathbf{c}$ in the presence of lithium diisopropyl amide at $-78{ }^{\circ} \mathrm{C}$ led to diastereoisomeric mixture of 4a-c (1:1 ratio of erythro and threo, respectively). As described in literature, recrystallization of $\mathbf{4 a}$ from EtOAc gave rise to pure erythro diastereoisomer. For the compounds $\mathbf{4 b}$ and $\mathbf{4 c}$ recrystallization was not successful and column chromatography ( $n$-hexane/EtOAc $5: 1$ to $1: 1$ ) was performed. Due to the very<smiles>COC(=O)CCl</smiles><smiles></smiles><smiles>COc1ccccc1OCC(=O)OCC(C)C</smiles>

3<smiles>[R]c1ccc(C(O)C(Oc2ccccc2OC)C(=O)OC)c(C)c1[R]</smiles>
4a-c<smiles>[R20]c1ccc(C=O)c([R])c1[R20]</smiles>

1a: $\mathrm{R}_{1}=\mathrm{OH}, \mathrm{R}_{2}=\mathrm{OMe}, \mathrm{R}_{3}=\mathrm{H}$, 1b: $R_{1}=O H, R_{2}=O H, R_{3}=H$,

1c: $\mathrm{R}_{1}=\mathrm{H}, \mathrm{R}_{2}=\mathrm{OH}, \mathrm{R}_{3}=\mathrm{OH}$, 2a-5a: $R_{1}=O B n, R_{2}=O M e, R_{3}=H$ 2b-5b: $R_{1}=O B n, R_{2}=O B n, R_{3}=H$, 2c-5c: $R_{1}=H, R_{2}=O B n, R_{3}=O B n$, 6a: $\mathrm{R}_{1}=\mathrm{OH}, \mathrm{R}_{2}=\mathrm{OMe}, \mathrm{R}_{3}=\mathrm{H}$ 6b: $\mathrm{R}_{1}=\mathrm{OH}, \mathrm{R}_{2}=\mathrm{OH}, \mathrm{R}_{3}=\mathrm{H}$ 6c: $\mathrm{R}_{1}=\mathrm{H}, \mathrm{R}_{2}=\mathrm{OH}, \mathrm{R}_{3}=\mathrm{OH}$

Scheme 1 Synthesis of $\beta-O-4$ type lignol compounds. 
similar elution time, it was difficult to separate both diastereoisomers and only the erythro diastereoisomer was purely separated.

The isolated compounds were reduced with lithium aluminum hydride and benzyl groups were cleaved by palladium-catalyzed hydrogenation yielding $\mathbf{6 a - c}$. Formation of the desired dilignols was confirmed by NMR spectroscopy and elemental analysis. The ESI-MS spectra of the ligands were measured in methanol or in acetonitrile. Overall the positively charged $\mathrm{Na}^{+}$adducts, with $\mathrm{m} / \mathrm{z}$ values of 329 (6a and $\mathbf{6 b}$ ), were detected. Lignols were isolated in low to moderate yields due to the crucial purification step including the separation of diastereoisomers. Thus in this step the yield of the pure erythro diastereoisomers was between $7 \%$ and $20 \%$. The Fe(III) complexes were synthesized by deprotonation of the ligand with potassium hydroxide and addition of iron(III) chloride in methanolic solution (see ESI $\dagger$ ). The complexes $7 \mathbf{b}$ and $7 \mathbf{c}$ were isolated in low to moderate yields $(7-27 \%)$ and characterized by standard analytical methods. We presume that similar to analogous Fe(III) catechol coordination compounds, dinuclear complexes with two lignols bridging two iron centers were obtained. The mass spectra of the complexes display, similar to isolated and characterized catechol complex, one negatively charged fragment with $\mathrm{m} / \mathrm{z}$ value of 664 , which can be assigned to $\mathrm{Fe}(\text { lignol })_{2}{ }^{-}$. All detected molecular peaks of the complexes showed the expected isotopic iron pattern. Also elemental analysis, electrochemical studies and complex formation studies support our proposed structures.

\section{Cyclic voltammetry}

The electrochemical behavior of the ligands and complexes was studied in order to estimate the possibility of iron reduction under physiological conditions. The proposed mechanism of iron release in natural humic acid complexes includes the photoreduction of $\mathrm{Fe}(\mathrm{III})$ to $\mathrm{Fe}(\mathrm{II}) .{ }^{36} \mathrm{Fe}(\mathrm{II})$ has low affinity to AHS, dissociates from the complex and can be uptaken by the microorganisms. Although Fe(II) undergoes oxidation in oxygenated seawater, the steady state concentration of Fe(II) remains higher due to this reduction process. ${ }^{44}$ Thus redox potentials present important information regarding the bioavailability of iron and cyclic voltammetric measurements of $\mathbf{6 b}$ and $\mathbf{6 c}$ were performed in aqueous solution at various $\mathrm{pH}$ values in the absence and in the presence of iron(III) ions. Representative cyclic voltammograms are shown in Fig. 1 for $\mathbf{6 b}$ and catechol as reference, and electrochemical data are presented in Table S1 (ESI $\dagger$ ). A reversible $\left(E_{1 / 2}=0.00 \mathrm{~V}\right)$ and a quasi-reversible process $\left(E_{1 / 2}=+0.82 \mathrm{~V}\right)$ can be observed at $\mathrm{pH} 3.7$ in the case of $\mathbf{6 b}$. The reversible process might belong to the one-electron transfer between the catechol and the semiquinone radical. ${ }^{45}$ On the other hand mostly irreversible oxidation peaks appear at $\mathrm{pH}>8.8$, which is the $\mathrm{pH}$ range where the ligand $\mathbf{6 b}$ is present in its monodeprotonated $\left(\mathrm{HL}^{-}\right.$) form (Fig. S4A, ESI $\dagger$ ). The current maximum of the cathodic peak at $+0.65 \mathrm{~V}$ is decreasing with increasing $\mathrm{pH}$ and a novel oxidation peak appears at $+0.50 \mathrm{~V}$ and becomes dominant at $\mathrm{pH}$ 9.89, but disappears at $\mathrm{pH}>12$. In addition a new reduction peak is observed at $\mathrm{pH} \geq 11$ at $+0.27 \mathrm{~V}$. In the presence of half-equivalent iron(III) the position of the quasi-reversible peak pair is already shifted at $\mathrm{pH} 1.8$ and $\Delta E$ is somewhat lower $(+0.33 v s$. $+0.24 \mathrm{~V})$ (Fig. 3B), although practically no complex formation takes place under these conditions (Fig. S4B, ESI $\dagger$ ), because peaks belong to the unbound iron are observed at a lower potential range $\left(E_{1 / 2}=-0.15\right.$ at $\mathrm{pH} 2.7$, not shown here). The cathodic peak at $+0.42 \mathrm{~V}$ is disappearing with increasing $\mathrm{pH}$, while the oxidation peak still can be observed shifting from +0.76 to $+0.42 \mathrm{~V}$. The anodic peak is most probably related to the electrochemical oxidation of the ligand, which is mostly bound to the metal ion (e.g. 95\% of the ligand is coordinated at $\mathrm{pH} 8$ ).
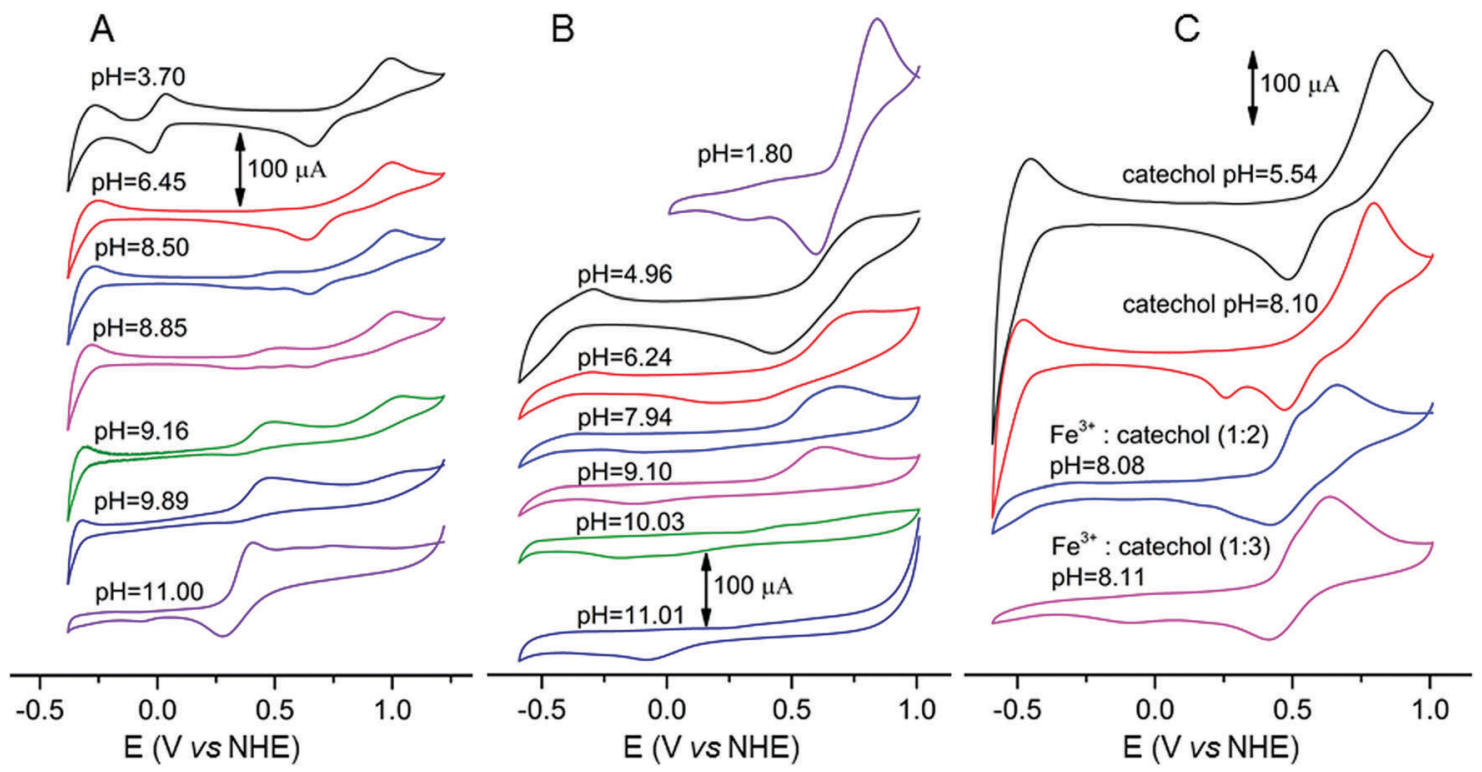

Fig. 1 Cyclic voltammograms of $\mathbf{6 b}(\mathrm{A})$ and the iron(III) $-\mathbf{6 b}(1: 2)(B)$ system at various $\mathrm{pH}$ values in aqueous solution, and for catechol (at $\mathrm{pH} 5.54$ and 8.00) and iron(III) - catechol $(1: 2,1: 3)$ system (at $\mathrm{pH} \sim 8.1$ ) for comparison (C). ( $\left.\mathrm{C}_{\mathrm{L}}=2.0 \mathrm{mM} ; \mathrm{I}=0.10 \mathrm{M}(\mathrm{KCl}) ; T=25^{\circ} \mathrm{C}\right)$. 
In addition a novel cathodic peak is seen at $c a$. $-0.1 \mathrm{~V}$ at $\mathrm{pH}>9$ where more and more tris-ligand species are assumed to be formed and the reduction process can be described to the iron(III)/iron(II) transition. Notably, only irreversible processes are observed at $\mathrm{pH}>5$. Overall, $\mathbf{6 c}$ behaves very similarly to $\mathbf{6 b}$; however, formal potentials $E_{1 / 2}$ of the ligand are always lower by 170-180 $\mathrm{mV}$ (Table S1, ESI $\dagger$ ). At the same time in the presence of iron(III) ions the observed anodic and cathodic peak positions are just slightly different in the case of the studied ligands. Comparing the recorded voltammograms of $\mathbf{6 b}, \mathbf{6} \mathbf{c}$ to those of catechol at $\mathrm{pH} \sim 8$ when iron(III) was added to the solution it can be noted that the oxidation peak of catechol $(+0.64 \mathrm{~V})$ appears at a similar potential as in the case of the other two ligands, while a cathodic peak with high intensity is seen at $+0.42 \mathrm{~V}$ and another smaller reduction peak appears at lower potentials $(+0.11 \mathrm{~V})$. In the case of catechol, iron(III) is present in the bis complex predominantly at $1: 2$ metal-to-ligand ratio at $\mathrm{pH} 8$ due to the formation of the higher stability complexes compared to ligands $\mathbf{6 b}$ and $\mathbf{6 c}(c f$. Fig. $\mathrm{S} 4 \mathrm{~B}$, ESI, $\dagger$ in the case of 6b) based on the determined stability constants (vide infra). The isolated $\mathrm{Fe}(\mathrm{III})$ complexes $\mathbf{7 b}, \mathbf{c}$ of the respective dilignols ligands $\mathbf{6 b}, \mathbf{c}$ were investigated for comparison. However, due to the lower aqueous solubility the experiments were performed in DMF (Fig. S1, ESI $\dagger$ ). Under these conditions the two irreversible reduction peaks with values $-0.07 \mathrm{~V}$ and $+0.52 \mathrm{~V}$ and an irreversible oxidation peak at $+1.2 \mathrm{~V}$ were detected for $7 \mathbf{b}$ which
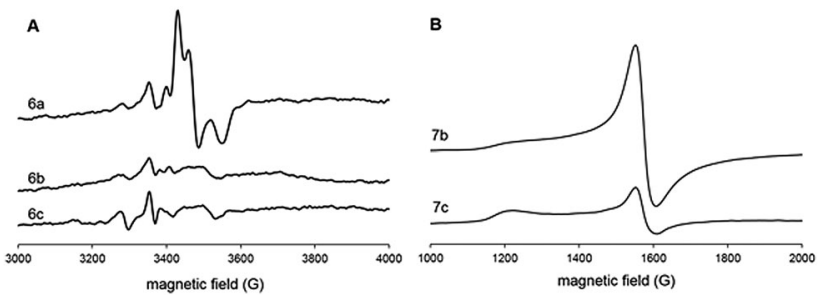

Fig. 2 EPR spectra of the ligands, $6 \mathbf{a}-\mathrm{c}(\mathrm{A})$, as well as of the iron complexes, $7 \mathbf{b}$ and $7 \mathbf{c}(\mathrm{B})$, measured at $9.43 \mathrm{GHz}$ and $90 \pm 1 \mathrm{~K}$. can be assigned to ligand and iron reduction. Complex $7 \mathbf{c}$ showed three irreversible reduction peaks with the values $+0.01 \mathrm{~V},+0.29 \mathrm{~V}$ and $+0.44 \mathrm{~V}$ and similar to $7 \mathbf{b}$ an oxidation peak at $+1.2 \mathrm{~V}$.

Overall, the observed reduction potentials of model ligands, complexes and in situ prepared iron(III) complexes are lying in the area accessible to photoreduction as well as for natural occurring reducing agents. ${ }^{46}$ These studies confirm that those dilignols can be seen as suitable model compounds for AHS regarding their redox activity.

\section{EPR spectroscopy}

EPR spectral analyses of the ligands $6 \mathbf{a}-\mathbf{c}$, revealed a $g$-factor of 2.0 similar to the free electron (Fig. 2). Thus, all ligands might represent organic free radicals. Santana-Casiano et al. showed that catechol-type structures can be readily oxidized in the presence of oxygen yielding stable radicals. ${ }^{47}$ Stable radicals were also detected in humic acids. ${ }^{48,49}$ The high stability of the free radicals can be explained by the delocalization of the electron over the phenol ring.

The hyperfine splitting of the signal indicates an interaction between the unpaired electron and magnetic hydrogen nuclei. The line pattern of the EPR spectrum suggests that the electron is delocalized over the carbon atoms of the aromatic ring. The EPR spectrum of the ligand, 6a, differs from the other ligands exhibiting a $g$-factor of approximately 1.9. The methoxy group at the aromatic ring might participate in the delocalization of the electron, thereby inducing the appearance of additional signals. The two iron complexes, $\mathbf{7 b}$ and $\mathbf{7 c}$, showed a distinct signal at $g=4.3$ (Fig. 2). This isotropic-looking line is characteristic of Fe(III) in the high spin state. By considering all experimental $g$-values for each of the Kramers' doublets, a rhombicity of 0.32 and 0.11 was determined for both complexes, suggesting low axial symmetry.

\section{Proton dissociation processes and lipophilicity of the ligands}

The proton dissociation constants of the studied ligands $\mathbf{6 a - c}$ were determined by $\mathrm{pH}$-potentiometric and UV-Vis spectrophotometric titrations in aqueous solution (Table 1). The first

Table 1 Proton dissociation constants $\left(\mathrm{p} K_{\mathrm{a}}\right)$ of ligands $\mathbf{6 a}-\mathrm{c}$ determined by various methods, $\lambda_{\max }$ and molar absorbance values $(\varepsilon)$ of the ligand species in the different protonates states, distribution (\%) and $n$-octanol-water distribution coefficients $(\log D)$ at $\mathrm{pH} 2.5$ and $8.3 .\left(T=25^{\circ} \mathrm{C} ; \mathrm{I}=0.1 \mathrm{M}(\mathrm{KCl})\right.$ )

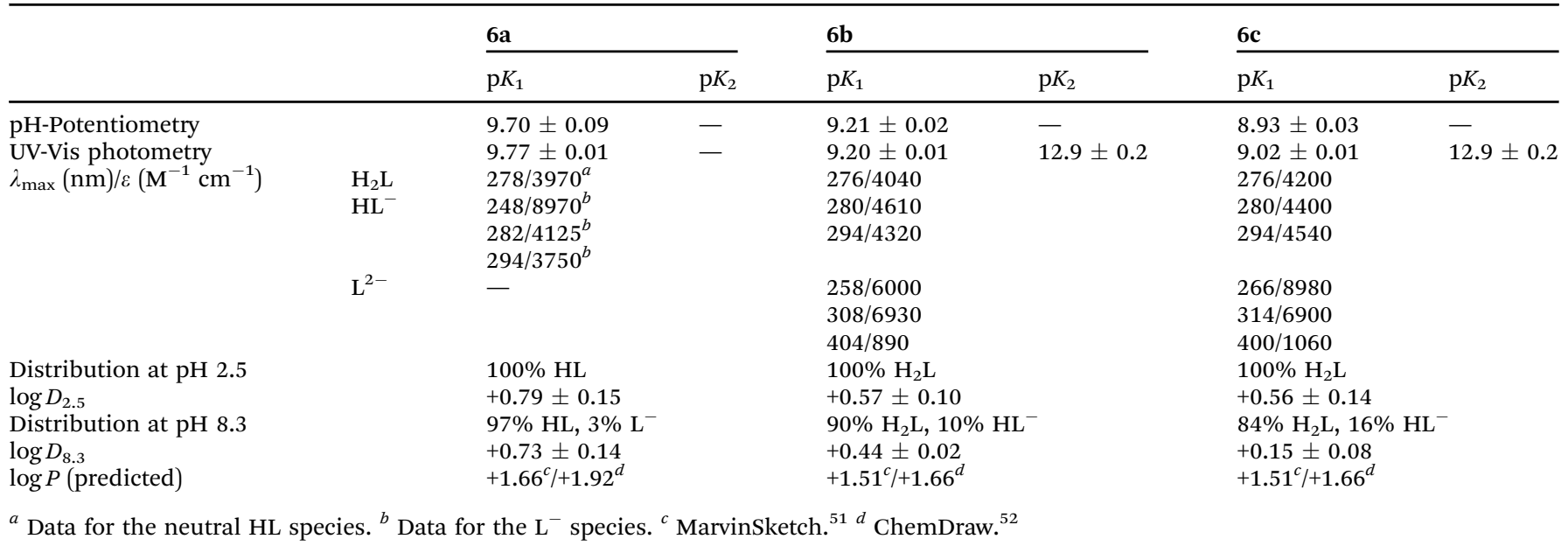


deprotonation process in all cases takes place at $\mathrm{pH}<11.5$, therefore $\mathrm{p} K_{1}$ values could be determined accurately by the evaluation of the $\mathrm{pH}$-potentiometric titration curves; on the other hand, these titrations were used to obtain the exact concentration of the ligands stock solutions and to check their stability in aqueous solution. Consecutive titrations showed that no ligand decomposition occurred in the $\mathrm{pH}$ range studied under an argon atmosphere and the stock solutions $(\mathrm{pH} \sim 1.8)$ were stable over $48 \mathrm{~h}$. The proton dissociation processes could be followed by UV-Vis spectrophotometric titrations as well, since the deprotonation of the hydroxyl functional groups is accompanied by characteristic spectral changes. However, the second step occurs only at $\mathrm{pH}>11.5$ and spectra had to be recorded at high $\mathrm{pH}$ values $(\mathrm{pH}>12.6)$ where the ionic strength of $0.10 \mathrm{M}$ could not be kept constant and the measurement of the $\mathrm{pH}$ values became uncertain due to the alkaline error of the glass electrode. Therefore the $\mathrm{p} K_{2}$ constants have fairly high experimental errors and should be considered as estimated values. The titrations were performed under strictly anaerobic conditions due to the susceptibility of the catechol type ligands towards oxidation. ${ }^{50}$ Representative UV-Vis spectra recorded at various $\mathrm{pH}$ values are shown for $\mathbf{6 b}$ in Fig. S2A and B (ESI $\dagger$ ). Proton dissociation constants and the spectra of the individual ligand species $\mathrm{H}_{2} \mathrm{~L}, \mathrm{HL}^{-}$, and $\mathrm{L}^{2-}$ (Table 1 and Fig. S2C, D, ESI $\dagger$ ) were calculated on the basis of deconvolution of the measured spectra. The formation of a new band with higher $\lambda_{\text {max }}$ values (294 $\mathrm{nm}$ ) can be observed due to the deprotonation of the first $\mathrm{OH}$ moiety. While the completely deprotonated form of the ligands $\left(\mathrm{L}^{2-}\right)$ in the case of $\mathbf{6} \mathbf{b}$ and $\mathbf{6 c}$ is characterized by a strong band at 308 and $314 \mathrm{~nm}$, and a weaker band at 404 and $400 \mathrm{~nm}$, respectively.

Comparing the $\mathrm{p} K_{1}$ values of $\mathbf{6 b}$ and $\mathbf{6 a}$ it can be clearly seen that the acidity of $\mathbf{6 a}$ is significantly weaker due to the electron donating effect of the methyl group, while $\mathbf{6 b}$ and $\mathbf{6 c}$ have similar $\mathrm{p} K_{\mathrm{a}}$ values, close to the reported values of catechol $\left(\mathrm{p} K_{1}=9.22\right.$ and $\left.\mathrm{p} K_{2}=13.0\right) .{ }^{50}$

The lipo-hydrophilic character $(\log D)$ of the ligands $6 \mathbf{a}-\mathbf{c}$ was studied at $\mathrm{pH} 2.5$ and 8.3 via the partitioning between $n$-octanol and water (Table 1, Fig. S7A and B, ESI $\dagger$ ). The ligands are present in their neutral forms at the chosen acidic $\mathrm{pH}$, thus $\log D_{2.5}$ can be considered as $\log P$ values. The predicted $\log P$ values (with ChemDraw and MarvinSketch programs) for these compounds are $c a$. one order of magnitude higher than the experimentally obtained ones; however, they show the same tendency. All results indicate that the methoxy derivative has a more lipophilic character compared to $\mathbf{6 b}, \mathbf{c}$, which have moderate hydrophilic character like the reference compound catechol. At the chosen slightly alkaline pH the ligands are partly deprotonated, which causes the increased hydrophilicity. We have made an attempt at determining the lipophilicity of the iron(III) complexes of the studied compounds, but a precipitate was formed and clogged between the two phases even at lower ligand concentration $(100 \mu \mathrm{M})$, which hindered the quantitative analysis. Comparing the spectra of the aqueous phase obtained after partitioning for the iron(III) containing samples in buffered solution and in seawater to that of the free ligand, it can be concluded that the unbound ligand-to-complex ratio is significantly changed in the case of the buffered solution. However, in seawater the absorbance values (thus concentration) were significantly decreased in both cases. The spectra recorded for the octanol phases (Fig. S7C and D, ESI $\dagger$ ) show unambiguously the presence of some iron(III) complexes in the organic solvent in addition to the unbound ligand despite the net charge of the complex even in the case of the seawater with the very high salt content.

\section{Complex formation processes of ligands}

The complex formation processes of the ligand $\mathbf{6 b}$ with iron(III) were studied primarily by $\mathrm{pH}$-potentiometry in aqueous solution. However, the complexation was found to be sluggish, especially in the acidic pH-range meaning that the equilibrium was not reached within $10 \mathrm{~min}$ as also reported for catecholates. ${ }^{50}$ Therefore UV-Vis spectrophotometry was applied to follow the complexation of $\mathbf{6 a - c}$ with iron(III) using longer waiting time in the $\mathrm{pH}$ range from 2 to 11 with the exclusion of air; and the process was found to be reversible under this condition. Spectra were recorded in the wavelength range 350-1000 $\mathrm{nm}$ where mostly the strong metal-to-ligand charge transfer (CT) bands can be seen and the non-coordinated ligands do not absorb. A representative spectrum series for the iron(III) - $6 \mathrm{c}(1: 3)$ system is shown in Fig. 3A, which shows characteristic changes upon increasing $\mathrm{pH}$. The $\lambda_{\max }$ values of the main $\mathrm{CT}$ band were decreased with increasing $\mathrm{pH}$ (Fig. 3B) and a well-isolated isosbestic point is observed at $530 \mathrm{~nm}$ at $\mathrm{pH}>7.5$ showing a clean transformation of a complex to another species, most probably due to the equilibrium between the bis- and tris-ligand complexes. The recorded spectra were deconvoluted resulting in the overall stability constants and the molar absorbance spectra of the $[\mathrm{FeL}]^{+},\left[\mathrm{FeL}_{2}\right]^{-}$and $\left[\mathrm{FeL}_{3}\right]^{3-}$ complexes of $\mathbf{6 b}$ and $\mathbf{6 c}$ (see data in Table 2 and Fig. $3 \mathrm{C}$ in the case of $\mathbf{6 c}$ ). In these complexes most probably the completely deprotonated ligands $\left(\mathrm{L}^{2-}\right)$ coordinate via an $\left(\mathrm{O}^{-}, \mathrm{O}^{-}\right)$donor set as it was reported for the reference compound, catechol, and for other catecholate derivatives. ${ }^{50,53,54}$ The coordination of the monoprotonated ligand $\left(\mathrm{HL}^{-}\right)$in the metal complexes is very rare and observed only in compounds isolated from organic solvents; ${ }^{55,56}$ however, it was also suggested for the iron(III) in mono-ligand complexes of catechol by Hider et $a l^{54}$ It is noteworthy that intramolecular redox processes between $\mathrm{Fe}$ (III)-catecholate and $\mathrm{Fe}(\mathrm{II})$-semiquinone species are known to occur, mostly in the case of the mono complex. ${ }^{45,54,57}$ In addition existence of dimeric species $\left[\mathrm{Fe}_{2} \mathrm{~L}_{4}\right]^{2-}$ of catechol in the $\mathrm{pH}$ range of the formation of the bis-complex was also suggested based on Mössbauer spectroscopy. This species was suggested to contain two equivalent sites and a bridging hydroxyl group. ${ }^{54}$ Spectrophotometry is not an adequate method to distinguish between the formation of $\left[\mathrm{Fe}_{2} \mathrm{~L}_{4}\right]^{2-}$ and $\left[\mathrm{FeL}_{2}\right]^{-}$ complexes with the same metal-to-ligand ratio. Therefore two kinds of models could be calculated for the studied systems using the titration data which consist of the formation of the mononuclear or the dinuclear complex, but the latter model gave somewhat poorer fits between the experimental and calculated absorbance values. The calculated molar absorbance spectra and $\lambda_{\max }$ values (Table 2 ) of the $[\mathrm{FeL}]^{+},\left[\mathrm{FeL}_{2}\right]^{-}$and $\left[\mathrm{FeL}_{3}\right]^{3-}$ 

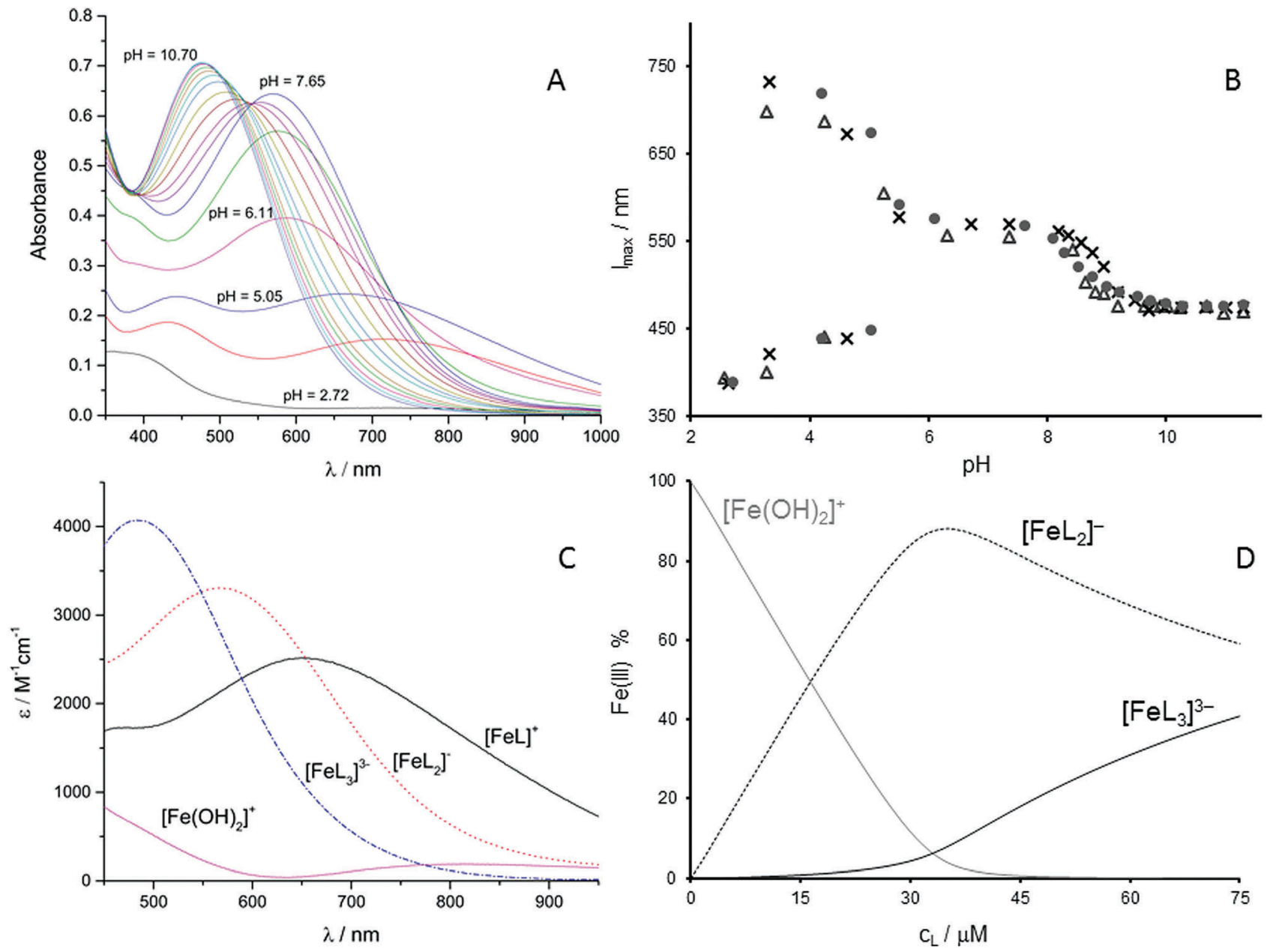

Fig. 3 UV-Vis absorbance spectra recorded for the iron(III) - $6 \mathrm{c}(1: 3)$ system at various $\mathrm{pH}$ values $(\mathrm{A})$ and the $\lambda_{\text {max }}$ values at $1: 3(\bullet), 1: 2(x)$ and $1: 1(\triangle)$ metal-to-ligand ratios $(B)\left(C_{L}=1.06 \mathrm{mM}\right)$. Calculated molar absorbance spectra of the individual complexes of $6 \mathrm{c}(\mathrm{C})$. Concentration distribution curves for the iron(III) $-6 \mathrm{c}$ system at various total concentrations of the ligand at a constant concentration of iron(III) and at pH 8.0 (D). $\left(C_{\mathrm{L}}=0-75 \mu \mathrm{M} ; C_{\mathrm{Fe}(I I I)}=15 \mu \mathrm{M}\right.$; $\left.\mathrm{pH}=8.0 ; I=0.10 \mathrm{M}(\mathrm{KCl}) ; T=25^{\circ} \mathrm{C}\right)$.

Table 2 Overall and stepwise stability constants $(\log \beta, \log K)$ for the iron(III) complexes of $\mathbf{6} \mathbf{b}$ and $\mathbf{6 c}$ determined by UV-Vis spectrophotometry, $\lambda_{\max }$ and molar absorbance values $(\varepsilon)$ of the complexes, and stability constants for the iron(III) complexes formed with catechol ${ }^{a}$ for comparison. $\left(T=25{ }^{\circ} \mathrm{C}\right.$; $I=0.1 \mathrm{M}(\mathrm{KCl}))$

\begin{tabular}{|c|c|c|c|c|}
\hline & & {$[\mathrm{FeL}]^{+}$} & {$\left[\mathrm{FeL}_{2}\right]^{-}$} & {$\left[\mathrm{FeL}_{3}\right]^{3-}$} \\
\hline $\mathbf{6 b}^{a}$ & $\begin{array}{l}\log \beta \\
\log K \\
\lambda_{\max }(\mathrm{nm}) / \varepsilon\left(\mathrm{M}^{-1} \mathrm{~cm}^{-1}\right)\end{array}$ & $\begin{array}{l}18.18 \pm 0.02 \\
18.18 \\
614 / 3200\end{array}$ & $\begin{array}{l}30.67 \pm 0.02 \\
12.49 \\
573 / 3550\end{array}$ & $\begin{array}{l}39.66 \pm 0.02 \\
8.99 \\
487 / 4170\end{array}$ \\
\hline $6 c^{b}$ & $\begin{array}{l}\log \beta \\
\log K \\
\lambda_{\max }(\mathrm{nm}) / \varepsilon\left(\mathrm{M}^{-1} \mathrm{~cm}^{-1}\right)\end{array}$ & $\begin{array}{l}18.32 \pm 0.02 \\
18.32 \\
657 / 2840\end{array}$ & $\begin{array}{l}33.13 \pm 0.02 \\
14.81 \\
567 / 3300\end{array}$ & $\begin{array}{l}43.34 \pm 0.02 \\
10.21 \\
482 / 4070\end{array}$ \\
\hline catechol $^{c}$ & $\begin{array}{l}\log \beta \\
\log K\end{array}$ & $\begin{array}{l}20.11 \\
20.11\end{array}$ & $\begin{array}{l}34.80 \\
14.69\end{array}$ & $\begin{array}{l}43.86 \\
9.06\end{array}$ \\
\hline
\end{tabular}

${ }^{a}$ Model with the dimeric complex: $\log \beta[\mathrm{FeL}]^{+}: 18.17 \pm 0.02, \log \beta\left[\mathrm{Fe}_{2} \mathrm{~L}_{4}\right]^{2-}: 64.43 \pm 0.03, \log \beta\left[\mathrm{FeL}_{3}\right]^{3-}: 39.45 \pm 0.02 .^{b}$ Model with the dimeric complex: $\log \beta[\mathrm{FeL}]^{+}: 18.40 \pm 0.02, \log \beta\left[\mathrm{Fe}_{2} \mathrm{~L}_{4}\right]^{2-}: 70.34 \pm 0.03, \log \beta\left[\mathrm{FeL}_{3}\right]^{3-}: 43.69 \pm 0.02 .^{c}$ Data are taken from ref. $50\left(I=c a .0 .15 \mathrm{M} ; T=2{ }^{\circ} \mathrm{C}\right)$.

complexes $\mathbf{6 b}$ and $\mathbf{6 c}$ are in accordance with literature data related to the catechol complexes. ${ }^{53}$ Since ligand $\mathbf{6 a}$ has lower water solubility compared to the other two studied compounds its complexation with iron(III) was studied via the ligand's bands at lower concentrations $(\sim 200 \mu \mathrm{M})$. The measured absorbance values in the absence and the presence of the metal ion (Fig. S3, ESI $\dagger$ ) were fairly similar suggesting the negligible formation of the iron(III) complexes under these conditions. The coordination 
of the monodentate phenolate type ligand is very weak similarly to the case of the phenol itself. ${ }^{58}$ Direct comparison of stability constants (Table 2) and concentration distribution curves calculated for the iron(III) complexes formed with $\mathbf{6 b}, \mathbf{6 c}$ (Fig. S5A, ESI $\dagger$ ) and catechol (Fig. S5B, ESI $\dagger$ ) shows that the studied ligands form somewhat lower stability complexes than catechol. (Notably, direct comparison of the $\log \beta$ values in this case is possible due to the similar stoichiometry of the complexes formed and the similar $\mathrm{p} K_{\mathrm{a}}$ values of the ligands.) In these cases the predominant formation of the bis complexes is found at neutral and slightly basic $\mathrm{pH}$ values. However, the actual speciation at pH 8 depends on the actual metal-to-ligand ratio (Fig. 3D).

In order to compare the metal ion binding abilities of the studied ligands to each other and to catechol or to other iron chelators (such as the catecholate-containing siderophores) pM $(p[\mathrm{Fe}(\mathrm{III})])$ values were calculated and plotted against the $\mathrm{pH}$. $p[\mathrm{Fe}(\mathrm{III})]$ is the negative logarithm of the equilibrium concentration of the free metal ion, while $p$ [unbound $\mathrm{Fe}(\mathrm{III})]$ values were also computed which show the summed equilibrium concentration of the unbound metal fraction involving the iron(III)-hydroxido species under the conditions employed $\left(c_{\mathrm{Fe}(\mathrm{III})}=1 \mu \mathrm{M}, \mathrm{Fe}(\mathrm{III}): \mathrm{L}=1: 10\right)$ (Fig. S6, ESI $\dagger$ ). These $\mathrm{pM}-\mathrm{pH}$ curves reveal the following stability trend: $\mathbf{6 b}<\mathbf{6 c}<$ catechol. $p[\mathrm{Fe}(\mathrm{III})]$ values 14.08 and 14.81 were obtained at $\mathrm{pH} 7.4$ for $\mathbf{6 b}$ and $\mathbf{6 c}$ respectively, which are significantly lower than that of the hexadentate catecholatetype enterobactin (35.5) or the hexadentate hydroxamate-type desferrioxamine B $(26.6)^{59}$ representing the much weaker iron(III) binding ability of the studied ligands compared to the naturally occurring siderophores.

\section{Algal growth experiments}

The understanding of the chemistry of these model compounds in aqueous solution provides useful information for the interpretation of algal studies. In order to evaluate the stability of the iron complexes and dilignol ligands in aqueous solution, time dependent UV-Vis studies in seawater, distilled water and water at $\mathrm{pH} 8$ have been performed. Both complexes $7 \mathbf{b}$ and $7 \mathbf{c}$ and the ligands $\mathbf{6 b}$ and $\mathbf{6 c}$ showed changes in their UV-Vis spectra over $24 \mathrm{~h}$ in seawater (Fig. S8, ESI $\dagger$ ) in contrast to $6 \mathrm{a}$ (see S9, ESI $\dagger$ ). The experiments in distilled water revealed no changes in absorbance in all tested compounds (see S10-S12, ESI $\dagger$ ). The time dependent spectra of $7 \mathbf{b}$ and $6 \mathbf{a}-\mathbf{c}$ in water at $\mathrm{pH} \sim 8$ (see S13 and S14, ESI $\dagger$ ), showed also an increase in the same signals as observed in seawater. The same behavior was observed for as time period of 21 days (duration of algal growth tests) and only ligand 6a showed an additional band after 14 days (see S15 and S16, ESI $\dagger$ ). Those results confirm that the established compounds are sufficiently stable for algal growth experiments. In order to elucidate the bioavailability of the iron complexes $\mathbf{7 b}, \mathbf{c}$ as well as the free ligands $\mathbf{6 a - c}$ to provide bioavailable iron, algal tests on C. salina and P. parvum have been performed. Those two species were intentionally chosen due to their wide occurrence and different biology. C. salina is a representative for unicellular green algae. The species react very sensitive to iron limitation. It has been recently reported, that cultures cultivated without iron or chelator EDTA showed poor growth. ${ }^{26,37,60}$ The second species $P$. parvum, is a unicellular haptophyte and this algae is able to grow under photoautotrophic and heterotrophic conditions. The species is also less sensitive to iron deficiency and can adapt to several environmental limitations. Moreover, $P$. parvum is well known for its toxicity and is a cause of mass fish deaths in coastal waters. Investigating both species may help to understand the alterations in iron uptake and preferences of each algae species towards different iron sources. All algae experiments were carried out in batch cultures, using three different nutrition setups. As full medium, seawater with micronutrient and vitamin solution as well as solution of $\mathrm{NaNO}_{3}, \mathrm{Na}_{2} \mathrm{SiO}_{3}, \mathrm{NaH}_{2} \mathrm{PO}_{4}$ as described by Guillard et al., ${ }^{27}$ were used (see Table S5, ESI $\dagger$ ). Those are common conditions for marine algae cultivation. The second set of control samples was lacking EDTA, which serves as chelator for iron and other metal ions. Those are useful negative references to study ligands 6a-c because these samples show the growth of the culture containing inorganic iron without chelating molecules. Third control set enables the evaluation of the culture growth without iron but with chelating molecules. With this control, the impact of other metal ions in solution can be elucidated. Theoretically, if the iron bound in complexes $\mathbf{7 b}$ and $\mathbf{7 c}$ is not bioavailable, the growth of the culture should be worse than the culture without iron. On the other hand if the ligands $\mathbf{6 a - c}$ cannot form bioavailable complexes with iron in solution, the growth of the culture should be comparable with the growth of the culture lacking EDTA.

The growth response of C. salina in the first experiment is shown in Fig. 4. As expected samples treated with medium without EDTA and iron showed poor growth. Samples treated with 6a reached similar low algae concentration confirming that this ligand cannot stabilize iron in solution. This result for 6a is not surprising because former complexation experiments and speciation studies revealed a low affinity of the ligand towards iron. In contrast, $\mathbf{6 b}, \mathbf{c}$ showed positive impact on the growth of $C$. salina. In case of $\mathbf{6 c}$ two different concentrations were chosen for the experiment. In the standard setup concentrations

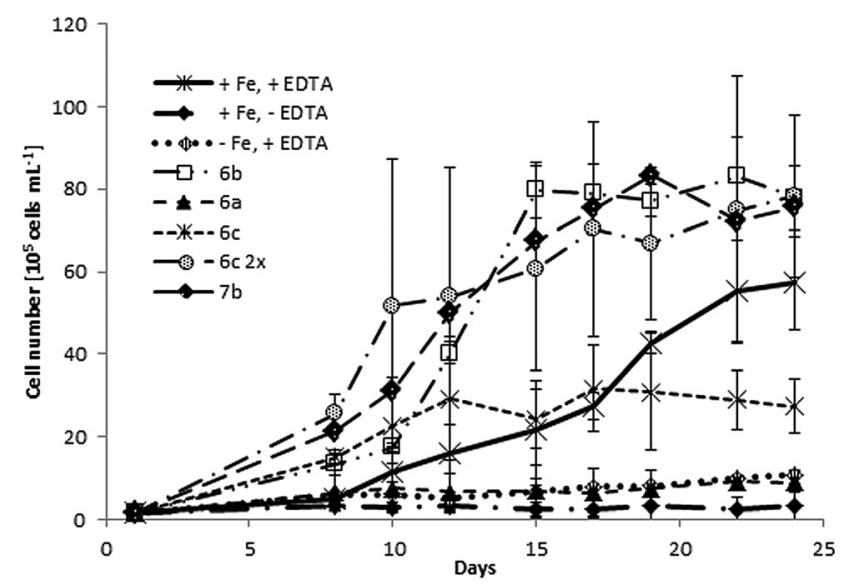

Fig. 4 Growth curves of $C$. salina (error bars: $\pm S D$ ) treated with model compounds $\mathbf{6 a}, \mathbf{6 b}, \mathbf{6 c}, \mathbf{6 c}(2 \times$ concentration) and $\mathbf{7 b}$ compared to control samples (+Fe, +EDTA; +Fe, -EDTA; -Fe, +EDTA). 
equal the EDTA concentration were applied. In this case the culture grew better than in samples lacking both EDTA and iron, but worse than in full medium. For the other samples with $\mathbf{6 c}$ we used twice higher concentration compared to that of EDTA because one EDTA molecule is able to bind one iron molecule, but at least two dilignols are needed to form a stable $\mathrm{Fe}$ (III) complex. For those samples, we observed better growth as for those with standard $\mathbf{6 c}$ concentration and even better than in full medium. Although ligand $\mathbf{6} \mathbf{b}$ was only used in same concentration (as EDTA), the growth response was similar to algae treated with complex $\mathbf{7 b}$. Those results revealed that $\mathbf{6 b}$ is more efficient than the respective complex $\mathbf{7 b}$ and ligand $\mathbf{6 c}$. Overall, both ligands $\mathbf{6 b}$ and $\mathbf{6 c}$ and the complex $7 \mathbf{b}$ are able to provide $C$. salina with bioavailable iron. Treatment with those model compounds showed better growth response than the samples cultivated in full medium. Comparison of the end-algal-concentration in samples treated with $\mathbf{6 b}, \mathbf{6 c}$ and $\mathbf{7 b}$ with our former experiments, where $C$. salina was treated with isolated AHS, showed similar values. Whereas samples containing AHS grew to $9 \times$ $10^{6} \pm 3.6 \times 10^{6}$ cells $\mathrm{mL}^{-1}$ and $10 \times 10^{6} \pm 6.7 \times 10^{5}{\text { cells } \mathrm{mL}^{-1}}^{-1}$ in each experiment, samples with model compounds reached approximately $7.7 \times 10^{6} \pm 1 \times 10^{6}$ cells $\mathrm{mL}^{-1}$. Algae cultures containing complex $7 \mathbf{c}$ as iron source reached only half of the concentration of the culture containing $7 \mathbf{b}$ (see Fig. S17, ESI $\dagger$ ). Table S2 (ESI $\dagger$ ) shows the end concentrations of the samples as well as the relation between the end-algae concentration of control samples to samples treated with model compounds from both experiments with $C$. salina.

Additionally to the maximal algae cell concentration, we also calculated the specific growth rate of algae for all tested compounds after 17 days of each experiment (which was the duration of the algal growth experiment for 7c (Table S3, ESI $\dagger$ ). Similar to the maximal algae cell concentrations, highest specific growth rates were observed for samples treated with $\mathbf{6 b}$ and $\mathbf{7 b}$.

The model ligands were also tested on $P$. parvum for they ability to bind and supply iron (Fig. S18, ESI $\dagger$ ). The culture of $P$. parvum was not as sensitive as $C$. salina to iron deficiency and we did not observe such pronounced effects on algal growth as for $C$. salina. In fact, the control with full medium reached almost the same concentration as the control without chelator (EDTA). Ligand $\mathbf{6 b}$ was tested in two concentrations, $(1 \times$ and $2 \times c$ (EDTA)); however, no impact on the final algae concentration was observed. In contrast to the experiments on $C$. salina samples treated with $\mathbf{6 a}$ showed similar growth response as $\mathbf{6 b}$. Ligand $\mathbf{6 c}$ displayed the only positive impact on $P$. parvum in comparison to control with full medium. Overall the end concentrations of $P$. parvum in the batch culture were significantly lower as the concentration of $C$. salina. The specific growth rates of algae for all tested compounds after 17 days are shown in Table S4 (ESI $\dagger$ ). Similar to the maximal algae cell concentrations, highest specific growth rates were observed for samples treated $\mathbf{6 c}$.

Summarizing the algal studies results, some of our herein presented compounds can be seen as suitable models for humic acids regarding the iron transport and ability to supply microorganisms with iron. In all experiments, the algal growth in samples without iron was strongly inhibited. For C. salina typical growth pattern, known from iron enrichment experiments, ${ }^{61,62}$ was observed. ${ }^{63,64}$

\section{Conclusions}

In this work, the novel dilignols-based models for aquatic humic acids were synthesized and extensively characterized. In order to investigate the redox properties, cyclicvoltammetric measurements were carried out. All of the compounds can be possibly reduced under biological conditions, which is in accordance with the properties of AHS. Various UV-Vis studies were performed in order to elucidate iron(III) complex formation constants, $\mathrm{p} K_{\mathrm{a}}$ values of the ligands, lipophilicity and the stability of the compounds in aquatic systems, especially in artificial seawater to verify the potential of the developed model to supply marine microorganisms with iron. Regarding the stability of the compounds we observed changes in spectra of the recorded in seawater which were the result of the deprotonation of free catecholic hydroxy groups. Comparison of the $\mathrm{p} K_{1}$ values of $\mathbf{6 b}, \mathbf{c}$ to $\mathbf{6 a}$ revealed a significantly weaker acidity of $\mathbf{6 a}$ due to the electron donating effect of the methyl group, while $\mathbf{6 b}$ and $\mathbf{6 c}$ have $\mathrm{p} K_{\mathrm{a}}$ values, which are similar to catechol. The lipophilicity studies of the ligands showed that methoxy derivative 6a has more lipophilic character compared to the catecholate derivatives, which have moderate hydrophilic character due to the partial deprotonation at increased $\mathrm{pH}$. Stability constants for the formation of the iron(III) complexes with model ligands were somewhat lower as for catechol whereas no data could be collected for 6a due to its very low affinity towards iron. At neutral and slightly basic $\mathrm{pH}$ values bis-complexes were predominant. The iron(III) binding ability of the studied ligands was found to be weaker as for the known siderophores. The ability to supply algae with iron was investigated in algal batch cultures. Ligands $\mathbf{6 b , c}$ bearing catecholic moiety showed very good impact on the culture of C. salina and P. parvum comparable with natural AHS and significantly better as for catechol itself. Also experiments on C. salina with isolated iron complexes gave similar results. However, guaiacylglycerol- $\beta$-guaiacyl ether did not enhance the growth of $C$. salina. Those results suggest that catecholic moieties can play an important role for complexation and stabilization of inorganic iron by humic substances.

\section{Conflicts of interest}

There are no conflicts to declare.

\section{Acknowledgements}

We thank the University of Vienna and the Austrian Science Fund (FWF) (P 25849-N19) for financial support. This work was also supported by the J. Bolyai Research Scholarship of the Hungarian Academy of Sciences (E.A.E.). The research was supported by National Research, Development and Innovation Office-NKFIH through project GINOP-2.3.2-15-2016-00038 and TÉT_15-1-2016-0024. 


\section{Notes and references}

1 W. G. Sunda and S. A. Huntsman, Mar. Chem., 1995, 50, 189-206.

2 N. M. Price, L. F. Andersen and F. M. M. Morel, Deep-Sea Res., Part A, 1991, 38, 1361-1378.

3 K. W. Bruland and S. G. Wells, Mar. Chem., 1995, 50, 1-2.

4 L. E. Brand, W. G. Sunda and R. R. L. Guillard, Limnol. Oceanogr., 1983, 28, 1182-1198.

5 P. W. Boyd and M. J. Ellwood, Nat. Geosci., 2010, 3, 675-682.

6 R. F. Nolting, L. J. A. Gerringa, M. J. W. Swagerman, K. R. Timmermans and H. J. W. de Baar, Mar. Chem., 1998, 62, 335-352.

7 J. H. Martin and R. M. Gordon, Deep-Sea Res., Part A, 1988, 35, 177-196.

8 J. H. Martin and S. E. Fitzwater, Nature, 1988, 331, 341-343. 9 J. H. Martin, R. M. Gordon and S. E. Fitzwater, Nature, 1990, 345, 156-158.

10 B. Hansen, P. K. Bjornsen and P. J. Hansen, Limnol. Oceanogr., 1994, 39, 395-403.

11 R. H. Byrne and D. R. Kester, Trans., Am. Geophys. Union, 1974, 55, 309.

12 J. F. Wu, E. Boyle, W. Sunda and L. S. Wen, Science, 2001, 293, 847-849.

13 E. L. Rue and K. W. Bruland, Mar. Chem., 1995, 50, 117-138.

14 J. F. Wu and G. W. Luther, Mar. Chem., 1995, 50, 159-177.

15 A. E. Witter and G. W. Luther, Mar. Chem., 1998, 62, 241-258.

16 C. M. G. Van Den Berg, Mar. Chem., 1995, 50, 139-157.

17 J. B. Neilands, Bacteriol. Rev., 1957, 21, 101-111.

18 S. M. Kraemer, Aquat. Sci., 2004, 66, 3-18.

19 S. I. Takagi, Soil Sci. Plant Nutr., 1976, 22, 423-433.

20 B. F. Matzanke, S. Anemuller, V. Schunemann, A. X. Trautwein and K. Hantke, Biochemistry, 2004, 43, 1386-1392.

21 R. Krachler, F. von der Kammer, F. Jirsa, A. Suphandag, R. F. Krachler, C. Plessl, M. Vogt, B. K. Keppler and T. Hofmann, Global Biogeochem. Cycles, 2012, 26, 1-9.

22 R. Krachler, R. F. Krachler, F. von der Kammer, A. Suephandag, F. Jirsa, S. Ayromlou, T. Hofmann and B. K. Keppler, Sci. Total Environ., 2010, 408, 2402-2408.

23 R. Krachler, F. Jirsa and S. Ayromlou, Biogeosciences, 2005, 2, 311-315.

24 X. W. Liu and F. J. Millero, Mar. Chem., 2002, 77, 43-54.

25 T. Hiemstra and W. H. van Riemsdijk, Mar. Chem., 2006, 102, 181-197.

26 R. Krachler, R. F. Krachler, G. Wallner, P. Steier, Y. El Abiead, H. Wiesinger, F. Jirsa and B. K. Keppler, Sci. Total Environ., 2016, 556, 53-62.

27 R. R. Guillard and J. H. Ryther, Can. J. Microbiol., 1962, 8, 229-239.

28 W. W. Gregg, M. E. Conkright, J. E. O’Reilly, F. S. Patt, M. H. H. Wang, J. A. Yoder and N. W. Casey, Appl. Opt., 2002, 41, 1615-1628.

29 C. B. Field, M. J. Behrenfeld, J. T. Randerson and P. Falkowski, Science, 1998, 281, 237-240.

30 J. A. Raven, New Phytol., 1988, 109, 279-287.

31 E. Ibisanmi, S. G. Sander, P. W. Boyd, A. R. Bowie and K. A. Hunter, Deep Sea Res., Part II, 2011, 58, 2113-2125.
32 S. A. Waksman and T. C. Cordon, J. Am. Chem. Soc., 1936, 58, 969-972.

33 S. A. Waksman and I. J. Hutchings, Soil Sci., 1936, 42, 119-130.

34 G. W. Ding, J. D. Mao and B. S. Xing, Commun. Soil Sci. Plant Anal., 2001, 32, 1991-2005.

35 J. B. Jahnel and F. H. Frimmel, Acta Hydrochim. Hydrobiol., 1995, 23, 31-35.

36 A. Blazevic, E. Orlowska, W. Kandioller, F. Jirsa, B. K. Keppler, M. Tafili-Kryeziu, W. Linert, R. F. Krachler, R. Krachler and A. Rompel, Angew. Chem., Int. Ed., 2016, 55, 6417-6422.

37 E. Orlowska, A. Roller, M. Pignitter, F. Jirsa, R. Krachler, W. Kandioller and B. K. Keppler, Sci. Total Environ., 2017, 577, 94-104.

38 E. Adler, Ind. Eng. Chem., 1957, 49, 1377-1383.

39 E. Adler, Wood Sci. Technol., 1977, 11, 169-218.

40 P. Merdy, E. Guillon, M. Aplincourt and J. Duomonceau, J. Chem. Res., Synop., 2000, 76-77.

41 E. Guillon, P. Merdy, M. Aplincourt, J. Dumonceau and H. Vezin, J. Colloid Interface Sci., 2001, 239, 39-48.

42 J. Buendia, J. Mottweiler and C. Bolm, Chem. - Eur. J., 2011, 17, 13877-13882.

43 F. Nakatsubo, K. Sato and T. Higuchi, Holzforschung, 1975, 29, 165-168.

44 F. M. M. Morel, R. J. M. Hudson and N. M. Price, Limnol. Oceanogr., 1991, 36, 1742-1755.

45 N. Schweigert, A. J. B. Zehnder and R. I. L. Eggen, Environ. Microbiol., 2001, 3, 81-91.

46 J. L. Pierre and M. Fontecave, Biometals, 1999, 12, 195-199.

47 J. M. Santana-Casiano, M. Gonzalez-Davila, A. G. Gonzalez and F. J. Millero, Aquat. Geochem., 2010, 16, 467-482.

48 A. Jezierski, F. Czechowski, M. Jerzykiewicz, Y. Chen and J. Drozd, Spectrochim. Acta, Part A, 2000, 56, 379-385.

49 R. W. Rex, Nature, 1960, 188, 1185-1186.

50 A. Avdeef, S. R. Sofen, T. L. Bregante and K. N. Raymond, J. Am. Chem. Soc., 1978, 100, 5362-5370.

51 ChemAxon L. Instant J Chem/MarvinSketch [Internet]. Budapest, Hungary: ChemAxon Ltd, 2012, available from: http://www.chemaxon.com.

52 ChemDraw Ultra program (Version 10.0, 1986-2005 Cambridge Soft.).

53 M. J. Sever and J. J. Wilker, Dalton Trans., 2004, 1061-1072, DOI: $10.1039 / \mathrm{b} 315811$ j.

54 R. C. Hider, A. R. Mohdnor, J. Silver, I. E. G. Morrison and L. V. C. Rees, J. Chem. Soc., Dalton Trans., 1981, 609-622, DOI: $10.1039 /$ Dt9810000609.

55 J. R. Dilworth, D. V. Griffiths, S. J. Parrott and Y. F. Zheng, J. Chem. Soc., Dalton Trans., 1997, 2931-2936, DOI: 10.1039/ A702935g.

56 B. A. Borgias, S. R. Cooper, Y. B. Koh and K. N. Raymond, Inorg. Chem., 1984, 23, 1009-1016.

57 C. G. Pierpont, Coord. Chem. Rev., 2001, 216, 99-125.

58 A. G. Desai and R. M. Milburn, J. Am. Chem. Soc., 1969, 91, 1958-1969.

59 W. R. Harris, K. N. Raymond and F. L. Weitl, J. Am. Chem. Soc., 1981, 103, 2667-2675. 
60 E. Orlowska, A. Roller, H. Wiesinger, M. Pignitter, F. Jirsa, R. Krachler, W. Kandioller and B. K. Keppler, RSC Adv., 2016, 6, 40238-40249.

61 M. Fujii and F. Chai, Deep Sea Res., Part II, 2009, 56, 2936-2947.
62 J. W. Pitchford and J. Brindley, J. Plankton Res., 1999, 21, 525-547.

63 A. S. Miron, M. C. C. Garcia, F. G. Camacho, E. M. Grima and Y. Chisti, Enzyme Microb. Technol., 2002, 31, 1015-1023. 64 C. J. Soeder, Arch. Hydrobiol., 1967, 63, 431-441. 